Original Research Article

\title{
Study of association between cholelithiasis and ABO blood group
}

\author{
Sengupta $S^{1}$, Sarkar $S^{2}$, Bala $T^{3}$ \\ ${ }^{1}$ Dr. Siladri Sengupta, Associate Professor, ${ }^{2}$ Dr. Subhadip Sarkar, Assistant Professor, Surgery, ${ }^{3}$ Dr. Tanuka Bala, Junior \\ Resident Surgery, all authors are affiliated with Department of Surgery, ESI-PGIMSR \&ESIC Medical College, Joka, \\ Kolkata, West Bengal, India.
}

Address for Correspondence: Dr. Tanuka Bala, Junior Resident, Department of Surgery, ESI-PGIMSR \& ESIC Medical College, Joka , Kolkata, West Bengal, India, Email: siladrisen2@gmail.com

\begin{abstract}
Introduction:The findings of Arid et al in 1953 regarding association between carcinoma of stomach and B blood group and then again in 1954 regarding association between peptic ulcer and O blood group opened a new approach to find association of blood group with other commonly occurring diseases. It is now well established that the blood group exhibits some relation with some diseases like nasopharyngeal carcinoma, duodenal ulcer, epistaxis, anemia and even cardiovascular diseases like coronary artery diseases and cardiac ischemia but such type of study with Gall stone formation is lacking. Objective: The present study therefore aims to find out regarding any association between cholethiasis and ABO blood Group. Method: Seven hundred patients were taken up for study from where by USG 100 patients were proven to be suffering from calculus cholelithiasis and confirmed by operations were considered as study group and the other 600 who were having other surgical problems without any gall stone admitted to this unit were taken as controls. The ABO blood group and $\mathrm{Rh}$ factor of both the groups were determined using the Tile or Slide testing methodand the frequency of occurrence of $\mathrm{ABO} \& \mathrm{Rh}$ blood group among gall stone disease patients (Study group) \& nongall stone population (Control group) was assessed. The frequency distribution of $\mathrm{ABO}$ blood group and $\mathrm{Rh}$ factor among the study population was compared with that of control population by Chi Square test. Results: The present study indicates that Cholelithiasis were found to be more common in O blood group individuals. Interpretation \& Conclusion: The present study suggests that A and $\mathrm{B}$ antigens were found to be a potential risk factor in the development of Gall stone disease as gall stone is more evident in group $\mathrm{O}$ individuals in comparison to non $\mathrm{O}$ individuals.
\end{abstract}

Key words: Cholelithiasis, ABO Blood Group, Association between gall stone and blood group.

\section{Introduction}

The findings of the ABO blood group in 1900 [1] and then $\mathrm{Rh}$ factor in 1940 [2] by Karl Landsteiner started a new beginning of blood banking and transfusion medicine. Since then there are numerous data regarding varying frequency of blood group worldwide based on different geographical location, ethnicity and socioeconomic conditions [3-8]. In India, similarly the prevalence of different blood group in different parts of India also varies.

The frequency of blood group B is highest among the Brahmins and Rajput's of Himachal Pradesh followed by $\mathrm{O}, \mathrm{A}$ and then $\mathrm{AB}[7]$ and also in North India [9], whereas in South India $\mathrm{O}$ group was found to be most common followed by $\mathrm{B}, \mathrm{A}, \mathrm{AB}[8]$. In west Bengal on the otherhand it is reported that amongst the studied

Manuscript Received: $5^{\text {th }}$ September 2017

Reviewed: $15^{\text {th }}$ September 2017

Author Corrected: $24^{\text {rd }}$ September 2017

Accepted for Publication: $30^{\text {th }}$ September 2017 population the B blood group is most common in both sexes followed by Group O, Group A and then Group AB [10].

The findings of Arid et al [11]in 1953 regarding association between carcinoma of stomach and B blood group and then again in 1954 [12] regarding association between peptic ulcer and $\mathrm{O}$ blood group opened a new approach to find association of blood group with other commonly occurring diseases. The ABH histo-blood group antigens are a set of polymorphic and inherited glycoconjugate structures that are expressed on the cell surfaces of human erythrocytes [13]. The presence and lack of blood antigens in some blood groups induce blood membrane changes, morphologically and functionally. The structure dependent functions of blood types can link the blood groups to health and diseases [14]. It is now well established that the blood group exhibits some 
relation with some diseases like nasopharyngeal carcinoma [15], duodenal ulcer [16], epistaxis [17], anemia [18] and even cardiovascular diseases like coronary artery diseases and cardiac ischemia (19.20). On the other hand, there are also some report regarding negative association ship between blood group and hypertension and diabetes mellitus [21,22].

Therefore, the present study aims to find out to examine the association between ABO blood group and gall stone disease so that a preventive measure can be applied to the risk blood group population.

\section{Material \& Methods}

Study design\&Settings: A total of 700 patients were included in the study of which (100) patients were diagnosed with gall stone labeled as Study group and (600) patients were with disease without any gall stone labeled as Control group. The study group was considered from the surgical patients reported to the said Surgical Unit II at ESIC Medical College, Joka,The study was approved by the Institutional ethical committee \& has no conflicts of interest.

Inclusion Criterion: All adult patients of both sexes with gall stone admitted in the said unit are included in study group whereas the patients of both sexes without any gall stone disease are included in our study as control group.

Exclusion criterion: Obese, diabetic, pregnant, menopausal women and the patients with hormonal replacement therapy for menopause are excluded from this study to rule out any role of hormonal and genetic factor that can contribute towards development of gall stone.

Participants: This study was conducted in Surgical Unit II at ESIC Medical College, Joka, Diamond Harbour
Road, Kolkata 700104, between Jan 2016 to June 2017. This study is based on simple random sampling with all gall stone disease patients reported and hospitalized in the aforesaid unit during the specified period are considered as Study group whereas the subjects for control group are selected from the non- gall stone patients reported to our unit on the basis of simple random sampling as this sampling satisfies all the statistical analytic methods.

Variables: Obesity, pregnancy, Hormonal therapy in menopause.

Quantitative variable: Age group between 15-70

Data Source: Hospital records and patients

Bias: Nil as random sampling was done

Study size; 700 patients.

Determination of blood group: With all aseptic precaution the whole blood of suspected anaemic patients was collected in fasting condition by venepuncture using disposable syringes. The ABO blood group and $\mathrm{Rh}$ factor of both the groups were determined using the Tile or Slide testing method [23], with the help of antisera A, antisera$\mathrm{B}$ and antisera-D and finally the frequency of occurrence of $\mathrm{ABO} \& \mathrm{Rh}$ blood group among diabetic \& non diabetic population was assessed.

Statistical Analysis: The frequency distribution of ABO blood group and $\mathrm{Rh}$ factor was expressed as percentage of each blood group and to establish the relationship between the blood group and Gall stone disease the frequency distribution (Observed frequency) of blood group among the entire Gall stone population i.e Study group $(\mathrm{N}=100)$ was compared with that of general non-gall stone population i.e Control group $(\mathrm{N}=600)$ and also with the reference frequency distribution of blood group among the general population [10] by Chi Square test [24] and a $\mathrm{P}$ value of 0.05 was considered significant for all the statistical test conducted.

\section{Results}

The frequency pattern of ABO and Rh blood group of male and female among studied population is shown in Table-I. It is found that amongst the studied population the B blood group is most common in both sexes followed by Group A, Group O and then Group AB. Statistical analysis by Chi Square test reflects that the observed frequency distribution does fit to the expected i.e. reference frequency distribution[10] or in otherwise there is no significant difference between the observed frequency distribution and reference frequency distribution (Fig 1) of West Bengal belt. It is also surprisingly found that the frequency distribution of Rh negative individuals is absolutelynil in both male and female population in this beltamong both control and studied group (Fig 1).

It is also found that the prevalence of O blood groupis highest 24 (48\%) followed by Group B - 13 (26\%), Group A - 9(18 \%) and then Group AB-3 (8\%) in studied population i.e. gall stoneaffected population (Table II). On the other hand, the observed frequency distribution of $\mathrm{ABO}$ blood group among control group i.e non gall stone affected population is predominantly B group followed by $\mathrm{O}, \mathrm{A}$ and then $\mathrm{AB}$. The Fig 2 also shows that both the ABO blood group distribution and $\mathrm{Rh}$ distribution among the study group is significantly $(\mathrm{P}<0.05)$ differs with the control group. 
Original Research Article

Table- 1: Sex wise frequency distribution of ABO blood group in Diamond Harbour belt of WB.

\begin{tabular}{|c|c|c|c|c|c|c|}
\hline Blood Group & \multicolumn{2}{|c|}{ Male (N=312) } & \multicolumn{2}{c|}{ Female (N=288) } & \multicolumn{2}{c|}{ Total } \\
\hline & $\begin{array}{c}\text { Absolute } \\
\text { Value }\end{array}$ & $\begin{array}{c}\text { Frequency } \\
\text { distribution } \\
(\%)\end{array}$ & $\begin{array}{c}\text { Absolute } \\
\text { Value }\end{array}$ & $\begin{array}{c}\text { Frequency } \\
\text { distribution } \\
(\%)\end{array}$ & $\begin{array}{c}\text { Absolute } \\
\text { Value }\end{array}$ & $\begin{array}{c}\text { Frequency } \\
\text { distribution (\%) }\end{array}$ \\
\hline A & 62 & 20 & 70 & 24 & 132 & 22 \\
\hline B & 124 & 40 & 120 & 42 & 244 & 41 \\
\hline AB & 42 & 13 & 32 & 11 & 74 & 12 \\
\hline O & 84 & 27 & 66 & 23 & 150 & 25 \\
\hline
\end{tabular}

Table- 2: Distribution of blood group among control and study group.

\begin{tabular}{|c|c|c|c|c|}
\hline \multirow{2}{*}{ Blood group } & \multicolumn{2}{c|}{$\begin{array}{c}\text { Control (Non Gall bladder stone } \\
\text { affected population) N=600 }\end{array}$} & \multicolumn{2}{c|}{$\begin{array}{c}\text { Study Group (Gall Bladder stone } \\
\text { affected population) } \mathbf{N = 1 0 0}\end{array}$} \\
\hline & Absolute Value & Frequency (\%) & Absolute Value & Frequency (\%) \\
\hline A & 132 & 22 & 18 & 18 \\
\hline B & 244 & 41 & 26 & 26 \\
\hline AB & 74 & 12 & 8 & 8 \\
\hline O & 150 & 25 & 48 & 100 \\
\hline Rh+ & 600 & 100 & 100 & 0 \\
\hline RH- & 0 & 0 & 0 & 48 \\
\hline
\end{tabular}

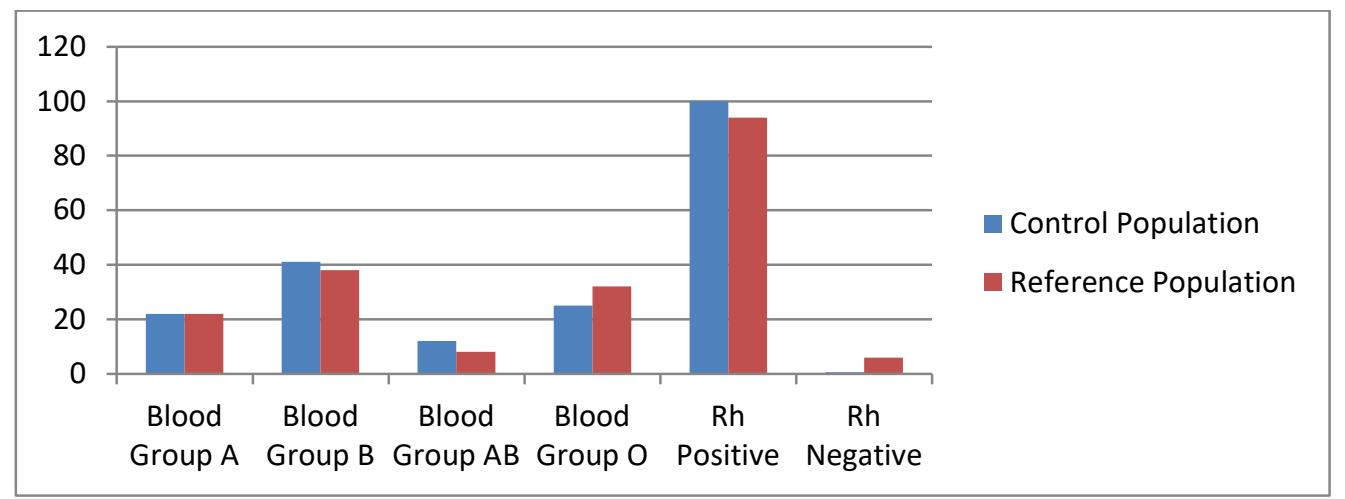

Fig-1: Frequency distribution of blood group in control population and reference population

\section{Discussion}

In various literatures there are reports of linking certain blood groups and the Rhesus typing with cholelithiasis and metabolic process including cholesterol metabolism [25]. The conclusion of these reports are variable as from blood group $\mathrm{A}$ in some to others in blood group $\mathrm{AB}$ and few suggests [26,27], no definitive relationship between calculus cholelithiasis and any particular blood group. Out of the good number of studies being conducted on this topic most are inconclusive as different authors are giving different conclusions. Chakravorti and Chakravorti [26] did a study on 321 patients and 688 controls in order to reach possible associations between $\mathrm{ABO}$ blood group and cholelithiasis. They were of the opinion that Blood
Group A subjects are having a higher risk of gall stone disease. Kratzer et al[28] had a study on 1030 blood donors and within that blood $\mathrm{AB}$ group was highest $(12.1 \%)$ in their series.Another study on 171 conservative patients with symptomatic gall stone were carried out by TatuJuVoneu andOmni Niemela [29] and revealed a predominance of Blood group A (44\%) followed by Blood group O (31\%) and B (17\%). They also further commented that Blood Group A had more stones with less than $25 \%$ cholesterol or no cholesterol than those with other group. Chen et al [27] in their series of 236 subjects having gall stone didn't show any correlation between blood group and cholecystitis. Monaci et al [30] studied 
on a group of 174 hospital patients to discover the incidence of blood group in comparison with a similar analysis of a representative sample (1872 people) of the Amiata community as a whole and it is felt that there is no statistical proof that one or more of this blood group is more prone to gall stone at least in Amiata community.

The present study reveals that gall stone disease is more common in blood group $\mathrm{O}$ population in comparison to non gall stone affected population, whereas it is also found that non $\mathrm{O}$ blood group like $\mathrm{A}, \mathrm{B}$ and $\mathrm{AB}$ are comparatively resistant to occurrence of gall stone as evident from the fact that the gall stone is found only $18 \%$ of blood group A (compared to $22 \%$ in general population); $26 \%$ of blood group B (compared to $41 \%$ in general population) and $8 \%$ of blood group $\mathrm{AB}$ (compared to $12 \%$ of general i.e. non gall stone population). This study is thus in accordance with the study of Chakravorti and Chakravorti [26] and Tatu Ju Voneu and Omni Niemela [29] or in other words it can be opined that occurrence of gall bladder stone has got relationship with $\mathrm{ABO}$ antigens as gallbladder stone is more common in $\mathrm{O}$ blood group population and less common in B blood group population.

Though there is a wide scope for further future studies on larger scale before an authentic conclusion can be drawn.

\section{Conclusion}

The present study suggests that A and B antigens were found to be a potential risk factor in the development of Gall stone disease as gall stone is more evident in group $\mathrm{O}$ individuals in comparison to non $\mathrm{O}$ individuals. The author hereby recommend to -

1. Take preventive measure to $A, B$ and $A B$ blood group individuals for gall stone.

2. Not to take cholesterol rich diet to prevent occurrence of gall stone.

3. To do the regular exercise for prevention of obesity.

\section{Contribution by authors:}

SiladriSengupta: Planning, Study designing, data analysis, Review of literature, Content writing.

SubhadipSarkar: Study designing, data analysis, Review of literature, Proof reading

TanukaBala: Study designing, data analysis, Review of literature, Proof reading.

Conflict of interest: None declared.

Funding: Nil, Permission from IRB: Yes

\section{References}

1. Landsteiner $\mathrm{K}$, "ZurKenntnis der antifermentativen, lytschen and agglutinierendenWirkungen des Blutserums und der Lymphe". Zentralblatt Bakreriologie., 1900; (27): 357-362.

2. Landsteiner K, Weiner AS.,, Anagglutinable factor in human blood recognized by immune sera for rhesus blood. Proc.Soc.Exp.Biol.Med., 1940;(43),223-244.

3. Garratty G, Glynn SA, McEntire R; Retrovirus Epidemiology Donor Study.ABO and Rh (D) phenotype frequencies of different racial/ethnic groups in the United States. Transfusion.2004; (5),703-6.

4. Racial \& Ethnic Distribution of ABO blood types, www.blood Bank.com, cited 15 ${ }^{\text {th }}$ March.2005.

5. Reid ME, Lomas -Francis C. The blood group antigen facts. $2^{\text {nd }}$ Edition.2004. New York; Elsevier Academic Press.

6. Chan KT. The ABO blood group frequency distribution of Singapore based on a blood donor sample. Singapore Med J. 1962;(3),3-15.

7. Mukherjee R, Khatriya GK., Distribution of blood groups among Brahmins and Rajputs in Himachal Pradesh. Anthropologist., 2004;6(4),293-294.

8. Das PK, Nair SC, Harris VK, Rose D, Mammen JJ, Bose YN, Sudarsanam A. Distribution of ABO and Rh-D blood groups among blood donors in a tertiary care centre in South India. Trop Doct. 2001 Jan;31(1):47-8.

9. Agrawal A, Tiwari AK, Mehta N, Bhattacharya P, Wankhede R, Tulsiani S, Kamath S. ABO and Rh (D) group distribution and gene frequency; the first multicentric study in India. Asian J Transfus Sci. 2014 Jul; 8 (2):121-5. doi: 10.4103/0973-6247.137452.

10. Basak A K, Tripathy SR, MajumderS,Frequency Distribution of ABO Blood Group and Rh Factor among the Local Domiciles of East Midnapore District, West Bengal, Ind J Pub H \& Dis., 2014; 5(3):273-75.

11. Aird I, Bentall HH, Roberts JA. A relationship between cancer of stomach and the ABO blood groups. $\mathrm{Br}$ Med J. 1953 Apr 11;1(4814):799-801.

12. Aird I, BentallHh, MehiganJa, Roberts Ja. The blood groups in relation to peptic ulceration and carcinoma of colon, rectum, breast, and bronchus; an association 


\section{Original Research Article}

between the $\mathrm{ABO}$ groups and peptic ulceration. Br Med J. 1954 Aug 7; 2(4883):315-21.

13. Sarafian V, Popov A, Taskov H. Expression of A, B and $\mathrm{H}$ blood-groupantigens and carcinoembryonic antigen in humantumours. Zentralbl Pathol. 1993 Nov; 139 (4-5):351-4.

14. Iwamoto S, Withers DA, Handa K, Hakomori S. Deletion of Aantigen in a human cancer cell line ig associated with reduced promoter activity of $\mathrm{CBF} / \mathrm{NF}-\mathrm{Y}$ binding region, and possibly with enhanced DNA methylation of A transferase promoter. Glycoconj J1999; 16 (10):659-66.

15. Seow LI, Kwa SB, Teoh CK. A Preliminary Survey Of Abo Blood Group Frequency In Nasopharyngeal Carcinoma In Chinese Patients. Singapore Med J. 1964 Sep; 4:93-5.

16. Clarke CA, Cowan WK, Edwards JW, Howel-Evans AW, Mcconnell RB, Woodrow JC, Sheppard PM. The relationship of the ABO blood groups to duodenal and gastric ulceration. Br Med J. 1955 Sep 10;2(4940):643-6.

17. Adhikari P, Pramanik T, Pokharel R, Khanal S. Relationship between blood group and epistaxis among Nepalese. Nepal Med Coll J. 2008 Dec;10(4):264-5.

18. Basak A K \&Maji K, Blood group and anemia: Exploring a new relationshipJ. Pub. Health \&Epi., 2013; 5 (1), 43-5.

19. Erikssen J, Thaulow E, Stormorken H, Brendemoen $\mathrm{O}$, Hellem A. ABO blood groups and coronary heart disease (CHD). A study in subjects with severe and latent CHD. Thromb Haemost. 1980 Jun 18;43(2):137-40.

20. Nydegger UE, Wuillemin WA, Julmy F, Meyer BJ, Carrel TP. Association of ABO histo-blood group B allele with myocardial infarction. Eur J Immunogenet. 2003 Jun; 30(3):201-6.
21. MajiKausik, BasakAsim Kumar, The study of probable relationship between blood group \& hypertension, Intn. J. physiol.(2015), 3(2):44-47.

22. Basak A K \&Maji K, Study of relationship between $\mathrm{ABO} \& \mathrm{Rh}$ blood group and type 2 diabetes mellitus (2016), Int. J. Med. Res \& Rev,, 4(11), 1965-1969.

23. Egesie UG, Egesie OJ, Usar I and Johnbull TO, Distribution of $\mathrm{ABO}$, Rhesus blood groups and $\mathrm{Hb}$ electrophoresis among the undergraduate students of Nigar delta University, Nigeria, Nijerian J. of Physiological Sciences, 2008 ;23(1-2), 5-8.

24. http://Graphpad.com/quick cals/chisquare2/.

25. Whincup PH, Cook DG, Phillips AN, Shaper AG. ABO blood group and ischaemic heart disease in British men. BMJ. 1990 Jun 30;300(6741):1679-82.

26. Chakravorty MR, Chakravorty $\mathrm{R}, \mathrm{ABO}$ blood groups in cholithiasisAnnGrnet 1979 22(3); 171-2.

27. Chen CY, Lu CL, Lee PC, Wang SS, Chang FY, Lee SD. The risk factors for gallstone disease among seniorcitizens: an Orientalstudy. Hepatogastroenterology. 1999 May-Jun;46(27):1607-12.

28. KratzerW, de Lazzer $\mathrm{K}$, Wiensneth $\mathrm{M}$, Muche R, Kachele V. The effect of ABO rhesus and Kell blood Group antigens on gall stone prevalence. A sonographic study of 1030 blood donors. DtschMedWochenschr 1999 May 14; 124(19); 579-83.

29. Juvonen T, Niemelä O. ABO blood group and gall stone disease. BMJ. 1992 Jul 4;305(6844):26-7.

30. Monaci R, Meoni S, Bini D, Morganti G. [Association between ABO blood groups and gallbladder calculi: a dissenting opinion]. Minerva Med. 1984 Oct 6;75(38): 2221-6.

\section{How to cite this article?}

Sengupta S, Sarkar S, Bala T. Study of association between cholelithiasis and ABO blood group. Int J surg Orthopedics. 2017;3(3):82-86.doi:10.17511/ijoso.2017.i03.06. 